\title{
Simple technique for detecting RNA viruses by PCR in single sections of wax embedded tissue
}

\author{
C J Woodall, N J Watt, G B Clements
}

\begin{abstract}
The detection of specific RNA species in wax-embedded tissue sections using the polymerase chain reaction (PCR) means that gene expression can be studied and RNA viruses detected in stored histological tissue samples. This technique potentially allows the distribution of gene expression and viral replication to be studied in finely subdivided tissues. A technique is presented that has been used successfully to detect short RNA target seqences (130-420 bases) from proto-oncogene Abelson, human enteroviruses, and the sheep retrovirus MaediVisna virus using RNA PCR in single wax sections $(20-30 \mu \mathrm{m})$. Various tissues were used which had not been deliberately prepared for this purpose. In a simple procedure hot xylene dewaxing is followed by acid phenol extraction of RNA and RNA PCR.
\end{abstract}

(F Clin Pathol 1993;46:276-277)

The PCR has been used to detect the nucleic acid in cells and pathogens in many different applications. A major requirement in the study of molecular pathological processes is the ability to reinvestigate tissue samples which have been stored in wax (this being the most common means of storage). Recently, PCR on DNA isolated from wax embedded material has been widely applied. ${ }^{1}$ This, however, does not detect RNA viruses, nor expressed genes (messenger RNA) in wax. Techniques are emerging to detect RNA molecules in wax blocks. ${ }^{2}{ }^{3}$ Here we present a rapid and easily executed technique to isolate and detect specific RNA molecules from single wax embedded tissue sections prepared from wax embedded blocks.

\section{Methods}

The following technique can deliver a result within 2 days. This technique is an adaptation of acid-phenol extraction ${ }^{4}$ and RNA PCR. ${ }^{5}$ Details of PCR primers used to detect proto-oncogene Abelson and enteroviruses are as described previously. ${ }^{6}$ Sections were prepared using a fresh microtome knife for each section, and taking care to avoid contamination by fragments of wax. Sections were collected individually in clean sterile Eppendorf tubes. The protocol used was as follows:
1 A single $20-30 \mu \mathrm{m}$ section is incubated in $10 \mathrm{ml}$ of xylene at $50^{\circ} \mathrm{C}$ for 20 minutes and the xylene carefully discarded. Repeat.

2 Wash tissue twice in $95 \%$ ethanol (RNase free) for 10 minutes at room temperature.

3 Hydrate tissue in $500 \mu \mathrm{l}$ of GITC buffer (4M guanidine isothiocyanate, $0.5 \%$ sarkosyl, $25 \mathrm{mM}$ sodium citrate, $100 \mathrm{mM}$ 2-mercaptoethanol, $\mathrm{pH} 7 \cdot 0$ ) at $4^{\circ} \mathrm{C}$ for 30 minutes.

4 Homogenise to release RNA and to shear DNA in the presence of $1 \mu \mathrm{g}$ of Escherichia coli R13 rRNA (Pharmacia).

5 Add $50 \mu \mathrm{l}$ of $2 \mathrm{M}$ sodium acetate, $\mathrm{pH}$ $4 \cdot 0, \quad 100 \mu \mathrm{l}$ of chloroform:isoamyl alcohol (49:1) and $500 \mu \mathrm{l}$ of water equilibrated phenol. Vortex vigourously and incubate for 15 minutes at $4^{\circ} \mathrm{C}$.

6 Centrifuge. Recover aqueous phase and precipitate RNA by addition of an equal volume of isopropanol. Resuspend the pellet in $300 \mu \mathrm{l}$ of GITC buffer and repeat the precipitation. Wash the pellet twice in $70 \%$ ethanol.

7 Reverse transcribe RNA in $10 \mathrm{mM}$ TRIS- $\mathrm{HCl}$, pH 8.3, $50 \mathrm{mM} \mathrm{KCl}, 5 \mathrm{mM}$ $\mathrm{MgC} 12 \cdot 6 \mathrm{H} 2 \mathrm{O}$ (Cetus PCR buffer), 0.09 Optical Density units of random hexamers, $200 \mu \mathrm{M}-\mathrm{MLV}$ reverse transcriptase in a $20 \mu \mathrm{l}$ volume, at $37^{\circ} \mathrm{C}$ for 45 minutes.

8 PCR appropriately for target sequence using $10-20 \mu \mathrm{l}$ of the reverse transcriptase reaction mix, 80-90 $\mu$ l of Cetus PCR buffer optimised for $\mathrm{MgC1} \cdot 6 \mathrm{H} 2 \mathrm{O}$ and 2 units of Taq polymerase for 35 cycles. PCR products may then be run directly on $2.5 \%$ agarose gels and stained with ethidium bromide.

\section{Results}

We have successfully used sections from blocks which were originally prepared using standard automated fixation and embedding techniques by several different pathology laboratories. Figures $1 \mathrm{~A}-\mathrm{C}$ show an example of an analysis of proto-oncogene Abelson and enterovirus sequences isolated from single sections of human spinal cords. In this case Abelson PCR acts as a positive control PCR to check the quality of the RNA samples before enterovirus PCR. Figure 1D shows a similar experiment performed on single sections from various tissues of sheep to detect the sheep retrovirus Maedi Visna virus (MVV). Abelson and enterovirus sequences are not detected if reverse transcription is omitted, or if RNA samples are treated with RNase before reverse transcription (data not shown). Further sensitivity and specificity may be 

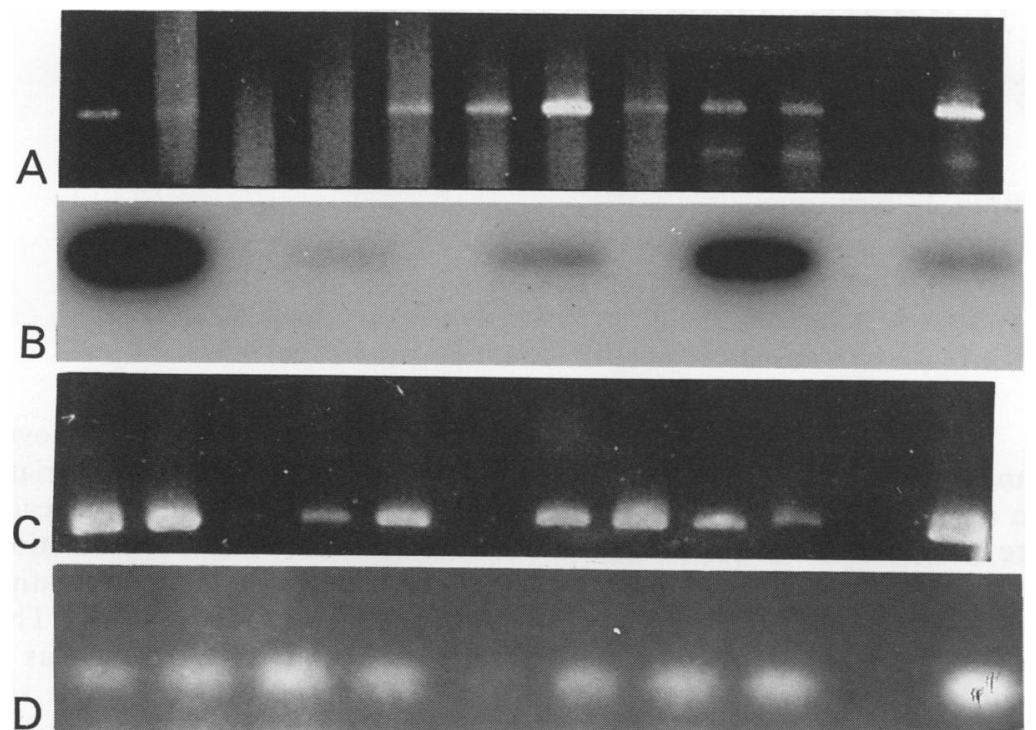

Figure 1 Examples of the detection of a primary 220 base pair PCR product from proto-oncogene Abelson by ethidium bromide staining of one fifth of a PCR reaction run on a $2.5 \%$ agarose gel. $(A)$ a primary 420 base pair enterovirus $P C R$ product detected by probing slot-blots of one half of a PCR reaction per slot. (B) A nested (secondary) 280 base pair human enterovirus PCR product amplified from the 420 base pair primary PCR product by a further 25 amplification cycles, where one fifth of the reaction was run on a $4 \%$ agarose gel and stained with ethidium bromide. (C) Secondary 130 base pair PCR product from the gag gene of $M V V$ detected in the same way as (C) after, respectively, 35 and 25 cycles of amplification with the primer pair GAGACATGGCGAAGCAAGGC (+), CCATAGACAGTTCCCTTCTG (-) (D). Each PCR product was amplified from a single wax embedded section. The two right hand lanes in figures $1 A, C$, and $D$ are (from left to right) negative and positive control samples.

obtained by slot-blotting the PCR product and probing with a labelled internal probe, or by nested PCR. We have found that PCR products obtained in this way are suitable for direct sequencing analysis, which has allowed enteroviral subtypes to be identified. The ability to detect these messenger RNA sequences in RNA isolated from a single section does illustrate the potential to detect a range of other messenger RNA molecules of interest.

\section{Discussion}

It has recently been reported that PCR can be used to detect RNA viruses in blocks of wax embedded tissues. ${ }^{2}{ }^{3}$ The technique reported here can be used to analyse single sections and is more rapid, sensitive, and robust. This technique has proved highly applicable to clinical research, and samples obtained after death from several sources (where fixation may have occurred in excess of 20 hours after death), including neurological tissues, have been shown to be positive for proto-oncogene Abelson and enterovirus. Undoubtedly, the type of fixative, the duration of fixation of tissue, and PCR target sequence length are important factors in determining the sensitivity of the detection of RNA molecules, as they are for detection of DNA sequences in wax embedded tissues. ${ }^{7}$ Consideration should be given to these variables when designing RNA PCR detection strategies. We would not recommend PCR target lengths in excess of 500 base pairs, but this protocol can sustain variations in tissue fixation. Consideration should also be given to prevent cross contamination of samples; we have used the same precautions applied to DNA PCR on wax embedded tissues ${ }^{1}$ This technique does not permit exact location of the signal within a section, but less sensitive techniques such as in situ hybridisation of adjacent sections may allow the distribution of RNA molecules within a section to be elucidated. Alternatively, microdissection of tissue sections and RNA-PCR amplification allows regions within the tissue to be analysed with greater resolution.

This work was funded through support of CJW by the Scottish Motor Neurone Disease Association (Regional Virus Laboratory) and the Agricultural and Food Research Council (UK) (Department of Veterinary Pathology). Special thanks are given to Professor David Graham, Department of Neuropathology, University of Glasgow, for the preparation of sections; Professor Peter Kennedy, Department of Neurology, University of Glasgow; and Doctor Jo Martin, Department of Morbid Anatomy, University of London, for the provision of samples used in this work. We also thank Ms. Miriam Riding for technical assistance.

Wright DK Manos MM. Sample preparation from parafin-embedded tissues. In: PCR Protocols: $A$ guide to methods and applications London: Academic Press, 1990: methods

2 Jackson DP, Lewis FA, Taylor GR, Boylston AW, Quirke $P$. Tissue extraction of DNA and RNA and analysis by the polymerase chain reaction. $f$ Clin Pathol 1990;43 499-504.

3 Redline RW, Genest DR, Tycko B. Detection of enteroviral infection in parafin-embedded tissue by the RNA polymerase chain reaction technique. Am f Pathol 1991 96:568-71.

4 Chomczynski P, Sacchi N. Single step method of RNA isolation by acid guanidium thiocyanate phenol chloroform extraction. Anal Biochem 1989;162:156-9.

5 Kawasaki E, Clarke SS, Coyne MY et al. Diagnosis of chronic myeloid and acute lymphocytic leukemias by detection of leukemia-specific mRNA sequences amplified in vitro. Proc Natl Acad Sci USA 1988;85:5698-702.

6 Gow JW, Behan WM, Clements GB, Woodall CJ, Riding Gow JW, Behan WM, Clements GB, Woodall CJ, Riding
M, Behan PO. Enteroviral RNA sequences detected by polymerase chain reaction in muscle of patients with postviral fatigue syndrome. $\mathrm{Br} \mathrm{Med} \mathcal{F}$ 1991;302:692-6.

7 Greer CE, Lund JK, Manos MM. PCR amplification from parafin-embedded tissues: recommendations on fixatives for long-term storage and prospective studies. PCR Methods and Applications 1991;1:46-50. 